Submission ID: 43770

\title{
Erosion Basement Heights at the Northern Slope of the Nepa Arch, the
} Nepa-Botuoba Anteclise (Suolakh Ridge)

P.I. Novikov* (SNIIGGiMS JC)

\section{SUMMARY}

The author briefly considers the history of studying the crystalline basement heights at the northern slope of the Nepa arch and the basement's influence on the oil and gas content of the overlying carbonate sediments. 
Эрозионные выступы фундамента на северном склоне Непского свода, НепскоБотуобинская антеклиза (Суолахский хребет)

\section{П.И. Новиков (АО СНИИГГиМС)}

Сибирская платформа является одним из важнейших источников восполнения минеральносырьевой базы Российской Федерации, однако ее территория в силу сложности геологического строения и недостаточности инфраструктуры изучена крайне слабо. Даже в относительно исследованных районах не решены некоторые важные геологические задачи, одной из которых является прогноз нефтегазоносности карбонатных отложений верхневендсконижнекембрийского нефтегазоносного комплекса. На территории юга Сибирской платформы верхневендско-нижнекембрийский нефтегазоносный комплекс распространен повсеместно и характеризуется значительными перспективами нефтегазоносности, крупные залежи нефти в нем известны на территории Непско-Ботуобинской антеклизы (Талаканское, Верхнечонское и др. месторождения), тем не менее геологоразведочные работы редко нацелены на этот комплекс из-за отсутствия надежных поисковых признаков, позволяющих прогнозировать залежи в карбонатных горизонтах. В настоящей статье в качестве такого признака рассматриваются эрозионные выступы фундамента и геологические причины существующей связи выступов фундамента и залежей углеводородов в карбонатных горизонтов над ними. В качестве примера подобной геологической обстановки выступает Суолахский хребет, выделенный по данным бурения, сейсмо- и гравиразведки на северном склоне Непского свода Непско-Ботуобинской антеклизы.

Кристаллический фундамент является сложным гетерогенным складчатым сооружением, которое слагают метаморфические и магматические образования с неоднородной плотностью. (Мегакомплексы..., 1987) Для территории юга Сибирской платформы характерна существенная расчлененность рельефа фундамента, картирование морфологических элементов его поверхности представляет собой непростую задачу. Вследствие сложных сейсмогеологических условий отражающий горизонт $\Phi$ (поверхность фундамента) прослеживается плохо даже при использовании современных технологий сейсморазведки. Суолахский хребет (рис. 1) выделен по материалам бурения скважины №1 вскрывшей под отложениями катангской свиты венда на глубине 1507 м железистые кварциты с прослоями, линзами магнетита и гематита. Вскрытая толщина кварцитов составила 104 м. На сейсмических разрезах проходящих вблизи или непосредственно через скважины, вскрывшие породы фундамента богатые магнетитом, четко проявлены поднятия по поверхности фундамента амплитудой до 200 и более метров, вытянутые вдоль интенсивной положительной магнитной аномалии (рис. 2), прослеживаемой в северо-западном направлении от р. Нюя по правобережью ее левого притока Тымпычан (УэльТымпычан) причтниной которой является намагниченность кварцитов.

По поводу генезиса Суолахского хребта существует несколько предположений. Ряд специалистов связывает его с интрузией. В заключении ГИС Трест "Сургутнефтегеофизика" и в литологическом описании керна скважины №1 интервал обозначен как "трапповая интрузия представленная магнетитовой рудой, от темно-серого до черного цвета, крепкая, массивная. С продольными линзовидными прожилками кварца вдоль оси керна..., отмечаются примазки пирита. Наблюдаются прослои красно-коричневого цвета". Другая версия была приведена в отчетах ФГУП "ВСЕГЕИ" (Ларичев А.И., 2014) и ООО "ЕМГЕО" (Фельдман И.С., 2011), авторы которых отнесли породы вскрытые скважиной к "вендским терригенным гематитмагнетит-кварцевым породам из приконтактовой зоны с молодой интрузией, внедрение которой сопровождалось интенсивными дислокациями вмещающих пород, гидротермальнометасоматическим процессом, а также их динамо- и пирометаморфизмом". Как указывается авторами, состав образовавшихся минералов свидетельствует о глубинном происхождении гидротермальных растворов. 


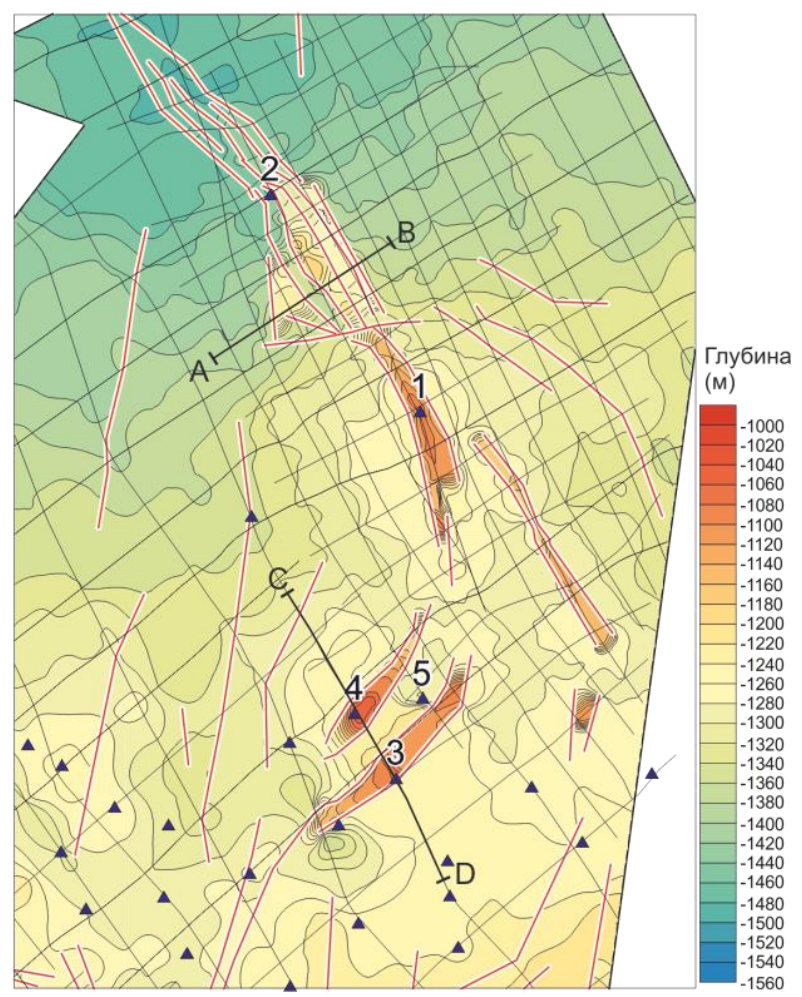

Условные обозначения

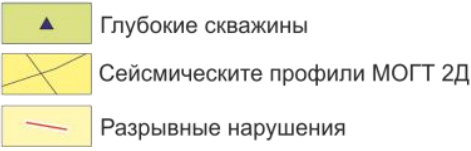

Рисунок 1. Структурная карта по поверхности фундамента.

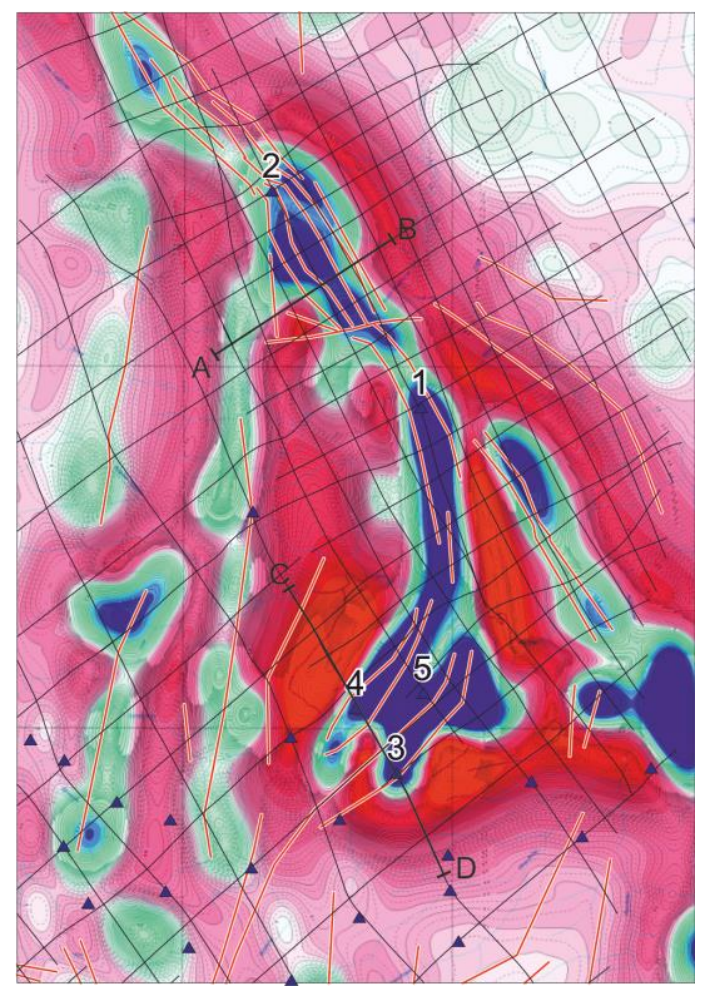

Рисунок 2. Карта изолиний локальной составляющей магнитного поля

Критический анализ ранее сделанных предположений о природе Суалахского хребта приведенных выше и наше дополнительное исследование керна вскрывших его скважин и особенностей проявления его в физических полях позволили нам предположить, что Суолахский хребет является эрозионным выступом фундамента дорифейского возраста, сложенным более устойчивыми к выветриванию породами, который к началу формирования вендских отложений представлял собой положительную форму рельефа. Изучение шлифа позволило определить породу в скважине №1 на глубине 1510,3м как железистый кварцит микро-тонко-мелкозернистый, наклоннослоистый, являющийся продуктом регионального метаморфизма первоначально вулканогенно-осадочных яшмоподобных пород, обогащенных гидроокислами железа, выносимого в процессе длительных подводных вулканических извержений и аккумулированного при участии ферробактерий. Суолахский хребет по сути является погребенным месторождением железистых кварцитов, которые как правило приурочены к докембрийским щитам и платформам, где они располагаются в протяжённых синклинальных структурах, вместе с другими осадочными и эффузивными горными породами. Железистые кварциты обычно имеют протерозойский или архейский возраст вместе с вмещающими горными породами тектонически деформированы и претерпели метаморфизм до гранулитовой фации. Они слагают крутопадающие пластообразные или линзовидные тела, согласные с вмещающими породами. Мощность одиночных тел от нескольких сантиметров до 800 м; часто при малой мощности железистые кварциты вместе с переслаивающимися с ними породами образуют залежи протяжённостью десятки и сотни километров.

Кроме того, в шлифе из базальной части успунской свиты в скважине №1 непосредственно над поверхностью фундамента в образце с глубины 1509,2м описана карбонатная порода с 


\section{EAGE}

обломочной структурой, брекчиевидная, пятнистая. Основная часть породы представлена обломками различного состава и генезиса и форменными элементами, сцементированными тонко-микрозернистым доломитом. Обломки пород (74 \%): хаотично расположенные в породе экстракласты и интракласты различные по размеру, форме и составу. Экстракласты (64 \%) представлены кварцем, кварцитами чистыми, без примесей, железистыми, возможно, кристаллическими сланцами, обломками с сидеритом, гидроокислами железа, гематитом, титано-магнетитом, лейкоксеном. Состав породы говорит о том, что успунская свита формировалась на размываемой поверхности выступа фундамента, т.к. содержит экстракласты пород слагающих Суолахский хребет.

В описываемом случае определяющую роль в картировании выступов фундамента сыграла намагниченность слагающих его пород а так же высокая амплитуда и контрастность, что привело к ярко выраженным дислокациям в вышележащей части разреза, включающей хорошо прослеживаемые отражающие горизонты (рис. 3). В случаях когда рельеф фундамента не так контрастен, выделение его форм может быть затруднительно из-за плохой прослеживаемости приуроченного к его кровле отражающего горизонта. Поэтому необходимо помнить о возможности существования достаточно расчлененного палеорельефа при интерпретации сейсмических разрезов.
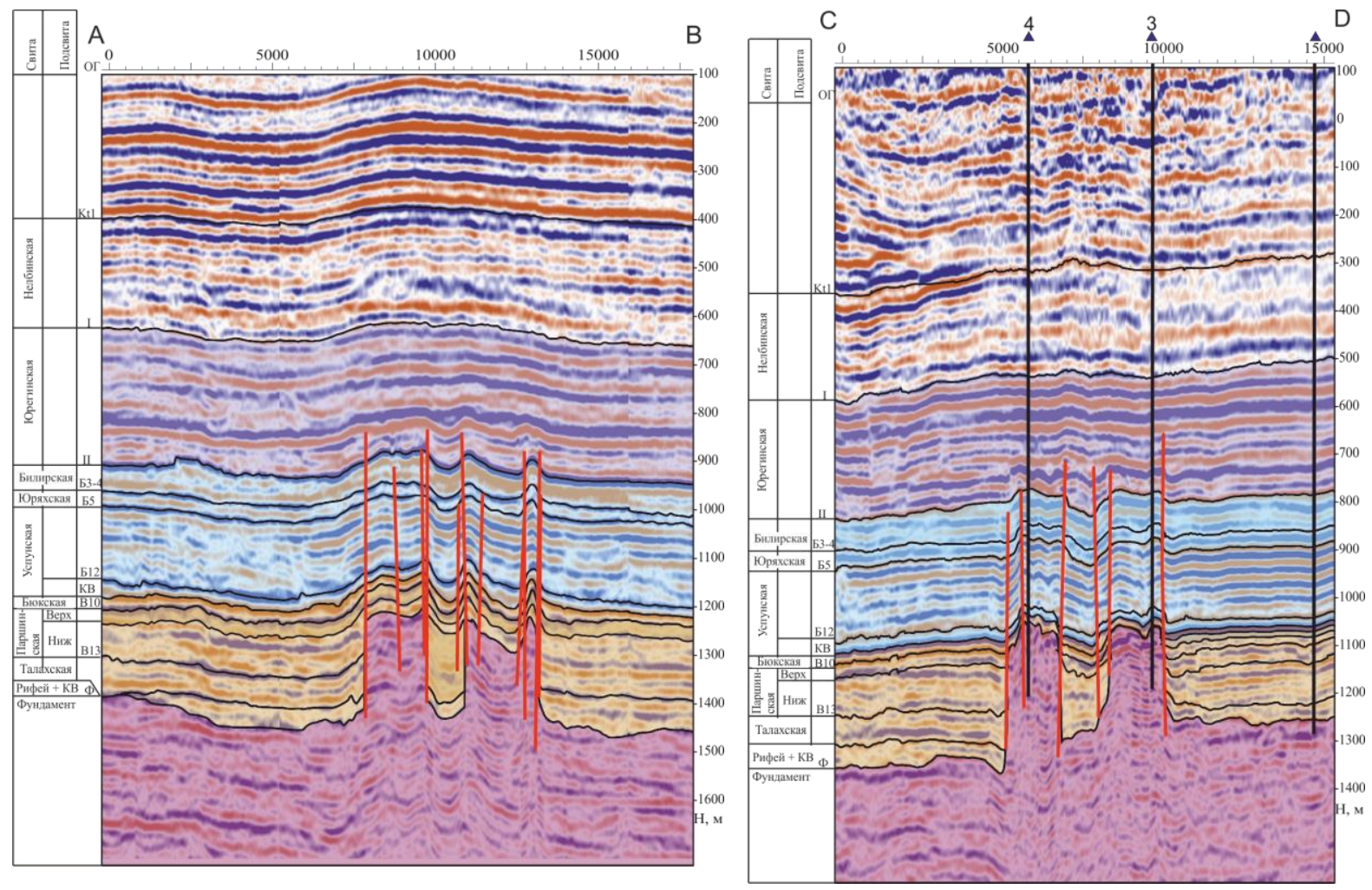

Рисунок 3. Фрагменты сейсмогеологических разрезов по линиям АВ и CD (см. рис. 1,2)

Эрозионные выступы фундамента могут по ряду причин положительно влиять на перспективы нефтегазоносности карбонатных горизонтов на исследуемой территории.

- В пределах таких выступов возможно формирование гидродинамических окон в зонах отсутствия или уменьшения толщин флюидоупоров терригенных комплексов, а так же активных разломов, что создает условия для миграции элизионных вод, которые могут как выщелачивать карбонатные породы, создавая кавернозный коллектор так и растворять заполняющие поровое пространство соли, улучшая коллекторские свойства.

- Также возможно развитие трещинных коллекторов, обусловленное наличием зон растяжения над выступами фундамента в результате неравномерного уплотнения отложений при литогенезе. 
- Первичные коллекторские свойства карбонатов могут быть улучшены над выступами фундамента по причине отставания этих участков в погружении, и, соответственно, формировании более благоприятных условий для роста рифоподобных построек. Некоторые исследователи отводят эрозионным выступам фундамента определяющую роль в формировании литологических ловушек за счет биомеханогенного формирования зернистых песчаноподобных карбонатов. (Гайдук А.В. и др., 2016). Бурение ряда высокодебитных скважин подтверждает полученные выводы

В пределах изучаемой территории сотрудниками ФГУП "СНИИГГиМС" в 2013г было рекомендовано исследовать южные отроги Суолахского хребта в плане продуктивности перекрывающих осадочных толщ основываясь на вышеизложенных соображениях подтвержденных притоком в скважине №1 (Мельников П.Н., 2013). Притоки газа полученные из осинского продуктивного горизонта в скважинах №3 и №4 (около 100 тыс.м³/сут) которые вскрыли останцы фундамента подтвердили перспективность зоны нефтегазонакопления вдоль этих палеогеоморфологических структур. Притоки из карбонатных пластов в скважинах, вскрывших выступы фундамента отмечаются и на соседних площадях глубокого бурения.

Насколько позволяют судить имеющийся в распоряжении автора фактический материал и данные из опубликованных источников (Гайдук А.В. и др., 2016), эрозионные выступы фундамента являются надежным поисковым признаком для залежей в карбонатных горизонтах подсолевого разреза юга Сибирской платформы. Благоприятные условия создаются благодаря целому ряду возможных факторов, вклад каждого из которых требует дополнительного изучения. Существует ряд ограничений в применении этого поискового признака, связанных со сложностью картирования пелеорельефа фундамента, неопределенностью природы взаимосвязи выступов фундамента с залежами, и ограниченности площадей залежей. Несмотря на это выступы фундамента имеют практическую значимость при прогнозе нефтегазоносности благодаря очень высоким показателям успешности поискового бурения в их пределах, и значительными дебитам в скважинах, вскрывающих связанные с ними залежи.

\section{Литература}

Опубликованная литература

1. Гайдук А.В., Митюков А.В., Филичев А.В., Петров А.Н., Мордвинцев М.В. Выявление перспективных и высокопродуктивных залежей УВ в древнем венд-раннекембрийском осадочном чехле Непско-Ботуобинской антеклизы на основании интерпретации современных геофизических данных. ГеоБайкал 2016 - Иркутск, Россия, 22-26 августа 2016 г.

2. Мегакомплексы и глубинная структура земной коры нефтегазоносных провинций Сибирской платформы: Труды СНИИГиМС /под ред. В.С.Суркова. - М.: Недра, 1987. $204 \mathrm{c}$.

Фондовая литература

1. Ларичев А.И. Совместная переобработка сейсморазведочных и электроразведочных работ в комплексе с фациальным анализом и иследованиями кернового материала карбонатных и терригенных отложений Кедрового ЛУ и прилегающих территорий, ФГУП «ВСЕГЕИ», 2014, 271 с., № 2125.

2. Фельдман И.С. Отчет о результатах тематических работ «Уточнение геологического строения и прогноз нефтегазоносности юго-восточной части Непско-Ботуобинской антеклизы на основании переинтерпретации архивных материалов электроразведочных работ и гравимагнитных данных», отв.исп. Фельдман И.С., ООО «ЕМГЕО», г. Москва, 2011 г.

3. Мельников П.Н. Комплексный геолого-геофизический анализ условий и перспектив нефтегазоносности на территории деятельности ОАО «Сургутнефтегаз» в Республике Саха (Якутия) и Иркутской области», отв.исп. П.Н.Мельников, СНИИГГиМС, Новосибирск, 2013 


\section{References}

Gayduk A.V., Mityukov A.V., Filichev A.V., Petrov A.N., Mordvintsev M.V. Vyyavleniye perspektivnykh i vysokoproduktivnykh zalezhey UV $\mathrm{v}$ drevnem vend-rannekembriyskom osadochnom chekhle Nepsko-Botuobinskoy anteklizy na osnovanii interpretatsii sovremennykh geofizicheskikh dannykh. GeoBaykal 2016 - Irkutsk, Rossiya, 22-26 avgusta 2016 g.

Megakompleksy i glubinnaya struktura zemnoy kory neftegazonosnykh provintsiy Sibirskoy platformy: Trudy SNIIGiMS /pod red. V.S.Surkova. - M.: Nedra, 1987. - 204 s.

Larichev A.I. Sovmestnaya pereobrabotka seysmorazvedochnykh i elektrorazvedochnykh rabot v komplekse $\mathrm{s}$ fatsial'nym analizom i isledovaniyami kernovogo materiala karbonatnykh i terrigennykh otlozheniy Kedrovogo LU i prilegayushchikh territoriy, FGUP «VSEGEI», 2014, 271 S., № 2125.

Fel'dman I.S. Otchet o rezul'tatakh tematicheskikh rabot «Utochneniye geologicheskogo stroyeniya i prognoz neftegazonosnosti yugo-vostochnoy chasti Nepsko-Botuobinskoy anteklizy na osnovanii pereinterpretatsii arkhivnykh materialov elektrorazvedochnykh rabot i gravimagnitnykh dannykh», otv.isp. Fel'dman I.S., OOO «EMGEO», g. Moskva, 2011 g.

Mel'nikov P.N. Kompleksnyy geologo-geofizicheskiy analiz usloviy i perspektiv neftegazonosnosti na territorii deyatel'nosti OAO «Surgutneftegaz» v Respublike Sakha (Yakutiya) i Irkutskoy oblasti», otv.isp. P.N.Mel'nikov, SNIIGGiMS, Novosibirsk, 2013 